\title{
Oligodendroglioma resection: a Surveillance, Epidemiology, and End Results (SEER) analysis
}

\author{
Ali A. Alattar, BS, ${ }^{1}$ Michael G. Brandel, BA, ${ }^{1}$ Brian R. Hirshman, MD, PhD, ${ }^{2,3}$ Xuezhi Dong, BA, ${ }^{1}$ \\ Kate T. Carroll, BA, ${ }^{1}$ Mir Amaan Ali, BS, ${ }^{1}$ Bob S. Carter, MD, PhD, ${ }^{2}$ and Clark C. Chen, MD, PhD ${ }^{2}$ \\ ${ }^{1}$ School of Medicine, and ${ }^{2}$ Division of Neurological Surgery, University of California, San Diego, California; and ${ }^{3}$ Computation, \\ Organization, and Society Program, School of Computer Science, Carnegie Mellon University, Pittsburgh, Pennsylvania
}

\begin{abstract}
OBJECTIVE The available evidence suggests that the clinical benefits of extended resection are limited for chemosensitive tumors, such as primary CNS lymphoma. Oligodendroglioma is generally believed to be more sensitive to chemotherapy than astrocytoma of comparable grades. In this study the authors compare the survival benefit of gross-total resection (GTR) in patients with oligodendroglioma relative to patients with astrocytoma.

METHODS Using the Surveillance, Epidemiology, and End Results (SEER) Program (1999-2010) database, the authors identified 2378 patients with WHO Grade II oligodendroglioma (O2 group) and 1028 patients with WHO Grade III oligodendroglioma (O3 group). Resection was defined as GTR, subtotal resection, biopsy only, or no resection. Kaplan-Meier and multivariate Cox regression survival analyses were used to assess survival with respect to extent of resection.
\end{abstract}

RESULTS Cox multivariate analysis revealed that the hazard of dying from $\mathrm{O} 2$ and $\mathrm{O} 3$ was comparable between patients who underwent biopsy only and GTR (O2: hazard ratio [HR] 1.06, 95\% confidence interval [Cl] 0.73-1.53; O3: HR 1.18, 95\% Cl 0.80-1.72). A comprehensive search of the published literature identified 8 articles without compelling evidence that GTR is associated with improved overall survival in patients with oligodendroglioma.

CONCLUSIONS This SEER-based analysis and review of the literature suggest that GTR is not associated with improved survival in patients with oligodendroglioma. This finding contrasts with the documented association between GTR and overall survival in anaplastic astrocytoma and glioblastoma. The authors suggest that this difference may reflect the sensitivity of oligodendroglioma to chemotherapy as compared with astrocytomas.

https://thejns.org/doi/abs/10.3171/2016.11.JNS161974

KEY WORDS oligodendroglioma; extent of resection; gross-total resection; survival; Surveillance, Epidemiology, and End Results; SEER; oncology

I DENTIFICATION of patients who would most likely benefit from resection remains a central tenet in the clinical practice of neurosurgical oncology.,21,25 A key consideration in this regard involves the intrinsic sensitivity of the cancer cells to chemotherapy or radiation therapy. Cancers with exquisite sensitivity to radiation or chemotherapy, such as primary CNS lymphomas (PCNSLs), typically only require a stereotactic needle biopsy for definitive tissue diagnosis. ${ }^{10-12,40}$ In contrast, patients afflicted with cancers of limited radiation or chemotherapy sensitivity, such as highgrade gliomas (HGGs), frequently benefit from maximal safe resection; ${ }^{14,16,19,36,37,42}$ where oligodendroglioma falls in this spectrum of surgical management paradigms remains an open question.
Oligodendroglioma is a rare form of brain cancer that arises from cell populations that give rise to oligodendrocytes; $;, 9,26,38,41,43,47,52$ it accounts for $4.9 \%$ of malignant adult brain cancers, with an incidence of 1-2 cases per million per year. ${ }^{41}$ Oligodendroglioma is further stratified by the WHO on the basis of histological appearance into Grade II (abbreviated in this study as O2) or Grade III (abbreviated in this study as O3). ${ }^{33}$ Given the rarity of O2s and O3s, they are often combined into a single entity or grouped with astrocytic tumors during clinical investigations, although the validity of such an approach remains unsubstantiated. $5,17,30,31,46,48,49$

In this study, we used the Surveillance, Epidemiology, and End Results (SEER; https://seer.cancer.gov) popula-

ABBREVIATIONS 75ST = the time in months at which $25 \%$ of the original patient population had died; $\mathrm{Cl}=$ confidence interval; EOR $=$ extent of resection; GTR = grosstotal resection; HGG = high-grade glioma; HR = hazard ratio; ICD-O-3 = International Classification of Diseases for Oncology-Third Edition; IQR = interquartile range; O2 = WHO Grade II oligodendroglioma; O3 = WHO Grade III oligodendroglioma; PCNSL = primary CNS lymphoma; SEER = Surveillance, Epidemiology, and End Results; STR = subtotal resection.

SUBMITTED July 27, 2016. ACCEPTED November 21, 2016.

INCLUDE WHEN CITING Published online May 12, 2017; DOI: 10.3171/2016.11.JNS161974. 
TABLE 1. Patient demographics and clinical characteristics

\begin{tabular}{|c|c|c|c|}
\hline Variable & O2 Group & O3 Group & Total \\
\hline No. of patients (\%) & $2378(69.82)$ & $1028(30.18)$ & $3406(100)$ \\
\hline Median age in yrs (IQR) & $41(32-51)$ & $47.5(38-58)$ & $43(33-53)$ \\
\hline \multicolumn{4}{|l|}{ Age category (\%) } \\
\hline$<18$ yrs & $146(6.14)$ & $19(1.85)$ & $165(4.84)$ \\
\hline $18-44$ yrs & $1258(52.9)$ & $418(40.66)$ & $1676(49.21)$ \\
\hline $45-59$ yrs & $702(29.52)$ & $376(36.58)$ & $1078(31.65)$ \\
\hline $60-74$ yrs & $216(9.08)$ & $177(17.22)$ & $393(11.54)$ \\
\hline$\geq 75$ yrs & $56(2.35)$ & $38(3.7)$ & $94(2.76)$ \\
\hline \multicolumn{4}{|l|}{ Race $(\%)$} \\
\hline White & $1765(74.22)$ & $753(73.25)$ & $2518(73.93)$ \\
\hline Black & $98(4.12)$ & $48(4.67)$ & $146(4.29)$ \\
\hline Asian/Pacific Islander & $135(5.68)$ & $75(7.3)$ & $210(6.17)$ \\
\hline Hispanic & $332(13.96)$ & $142(13.81)$ & $474(13.92)$ \\
\hline $\begin{array}{l}\text { American Indian/Alas- } \\
\text { kan Native }\end{array}$ & $26(1.09)$ & $<10(<1)$ & $31(0.91)$ \\
\hline $\begin{array}{l}\text { Other/unknown, non- } \\
\text { Hispanic }\end{array}$ & $22(0.93)$ & $<10(<1)$ & $27(0.79)$ \\
\hline \multicolumn{4}{|l|}{ Marital status $(\%)^{*}$} \\
\hline Single & $726(31.54)$ & $219(22.1)$ & $945(28.70)$ \\
\hline Married & $1343(58.34)$ & $626(63.17)$ & 1969 (59.79) \\
\hline $\begin{array}{l}\text { Separated, divorced, } \\
\text { widowed }\end{array}$ & $233(10.12)$ & $146(14.73)$ & $379(11.51)$ \\
\hline \multicolumn{4}{|l|}{$\operatorname{Sex}(\%)$} \\
\hline Male & $1325(55.72)$ & 585 (56.91) & $1910(56.08)$ \\
\hline Female & $1053(44.28)$ & $443(43.09)$ & 1496 (43.92) \\
\hline \multicolumn{4}{|l|}{ Tumor size in $\mathrm{cm}(\%)^{*}$} \\
\hline$<5$ & 859 (58) & $293(41.92)$ & $1152(52.84)$ \\
\hline $5-7$ & $442(29.84)$ & $248(35.48)$ & $690(31.65)$ \\
\hline$>7$ & $180(12.15)$ & $158(22.6)$ & $338(15.50)$ \\
\hline \multicolumn{4}{|l|}{ Tumor site (\%) } \\
\hline Frontal lobe & $1257(52.86)$ & $520(50.58)$ & $1777(52.17)$ \\
\hline Temporal lobe & $453(19.05)$ & $173(16.83)$ & $626(18.38)$ \\
\hline Parietal lobe & $232(9.76)$ & $124(12.06)$ & $356(10.45)$ \\
\hline Occipital lobe & $36(1.51)$ & $18(1.75)$ & $54(1.59)$ \\
\hline Brain stem & $8(0.34)$ & $3(0.29)$ & $11(0.32)$ \\
\hline $\begin{array}{l}\text { Overlapping lesion of } \\
\text { brain }\end{array}$ & $233(9.80)$ & $134(13.04)$ & 367 (10.78) \\
\hline Cerebrum & $60(2.52)$ & $26(2.53)$ & $86(2.52)$ \\
\hline Brain, NOS & $70(2.94)$ & $22(2.14)$ & $92(2.70)$ \\
\hline Ventricle, NOS & $13(0.55)$ & $5(0.49)$ & $18(0.53)$ \\
\hline Cerebellum, NOS & $16(0.67)$ & $3(0.29)$ & $19(0.56)$ \\
\hline \multicolumn{4}{|l|}{ Yr of diagnosis (\%) } \\
\hline 1999 & $139(5.85)$ & $62(6.03)$ & $201(5.90)$ \\
\hline 2000 & $210(8.83)$ & $94(9.14)$ & $304(8.93)$ \\
\hline 2001 & $213(8.96)$ & $119(11.58)$ & $332(9.75)$ \\
\hline 2002 & $234(9.84)$ & $98(9.53)$ & $332(9.75)$ \\
\hline 2003 & $221(9.29)$ & $84(8.17)$ & $305(8.95)$ \\
\hline 2004 & $213(8.96)$ & $96(9.34)$ & $309(9.07)$ \\
\hline 2005 & $172(7.23)$ & $82(7.98)$ & $254(7.46)$ \\
\hline 2006 & $213(8.96)$ & $102(9.92)$ & $315(9.25)$ \\
\hline
\end{tabular}

CONTINUED IN NEXT COLUMN "
» CONTINUED FROM PREVIOUS COLUMN

TABLE 1. Patient demographics and clinical characteristics

\begin{tabular}{cccc}
\hline \multicolumn{1}{c}{ Variable } & O2 Group & O3 Group & Total \\
\hline $\begin{array}{c}\text { Yr of diagnosis (\%) } \\
\text { (cont'd) }\end{array}$ & & & \\
\hline 2007 & $203(8.54)$ & $58(5.64)$ & $261(7.66)$ \\
\hline 2008 & $180(7.57)$ & $82(7.98)$ & $262(7.69)$ \\
\hline 2009 & $188(7.91)$ & $76(7.39)$ & $264(7.75)$ \\
\hline 2010 & $192(8.07)$ & $75(7.3)$ & $267(7.84)$ \\
\hline Radiotherapy (\%) & & & \\
\hline No & $1491(64.63)$ & $320(31.97)$ & $1811(54.75)$ \\
\hline Yes & $816(35.37)$ & $681(68.03)$ & $1497(45.25)$ \\
\hline Surgery (\%) & & & \\
\hline No surgery & $438(18.42)$ & $128(12.45)$ & $566(16.62)$ \\
\hline Local excision/biopsy & $550(23.13)$ & $222(21.6)$ & $772(22.67)$ \\
\hline STR & $557(23.42)$ & $310(30.16)$ & $867(25.46)$ \\
\hline GTR & $833(35.03)$ & $368(35.8)$ & $1201(35.26)$ \\
\hline Overall mortality rate (\%) & & & \\
\hline Living & $1788(75.19)$ & $544(52.92)$ & $2332(68.47)$ \\
\hline Deceased & $590(24.81)$ & $484(47.08)$ & $1074(31.53)$ \\
\hline
\end{tabular}

NOS $=$ not otherwise specified.

${ }^{*}$ Not all patients had complete data.

tion-based database to examine whether extended resection is associated with improved survival for $\mathrm{O} 2 \mathrm{~s}$ and $\mathrm{O} 3 \mathrm{~s}$. We further compared the SEER-based results to a comprehensive search of the published literature, and implications of these findings are discussed.

\section{Methods}

\section{Data and Study Population}

Data from the SEER database (1999-2010) were used for this study. SEER compiles cancer incidence and survival data from 18 registries in different regions of the US. These registries collect data on $28 \%$ of the US population from academic and nonacademic hospitals, and as such, are broadly representative of the US population as a whole (SEER Research Data 1973-2010). Patients were included in this study if they had a diagnosis of oligodendroglioma (International Classification of Diseases for OncologyThird Edition [ICD-O-3] histology code 9450) or anaplastic oligodendroglioma (ICD-O-3 histology codes 9451 and 9460) and no other cancer diagnosis. Patients of all ages were included.

\section{Primary End Point and Covariates}

The primary end point was overall patient survival, defined as the length of time in months from diagnosis to death from any cause or last follow up. All SEER patients with available surgical information were coded as having received 1) no surgery (code 00), 2) biopsy (code 20), 3) subtotal resection (STR; code 40), or 4) gross-total resection (GTR; code 55). ${ }^{37,42}$ Patients who did not undergo surgical intervention were coded as "no surgery." The operative report was used to distinguish patients who 


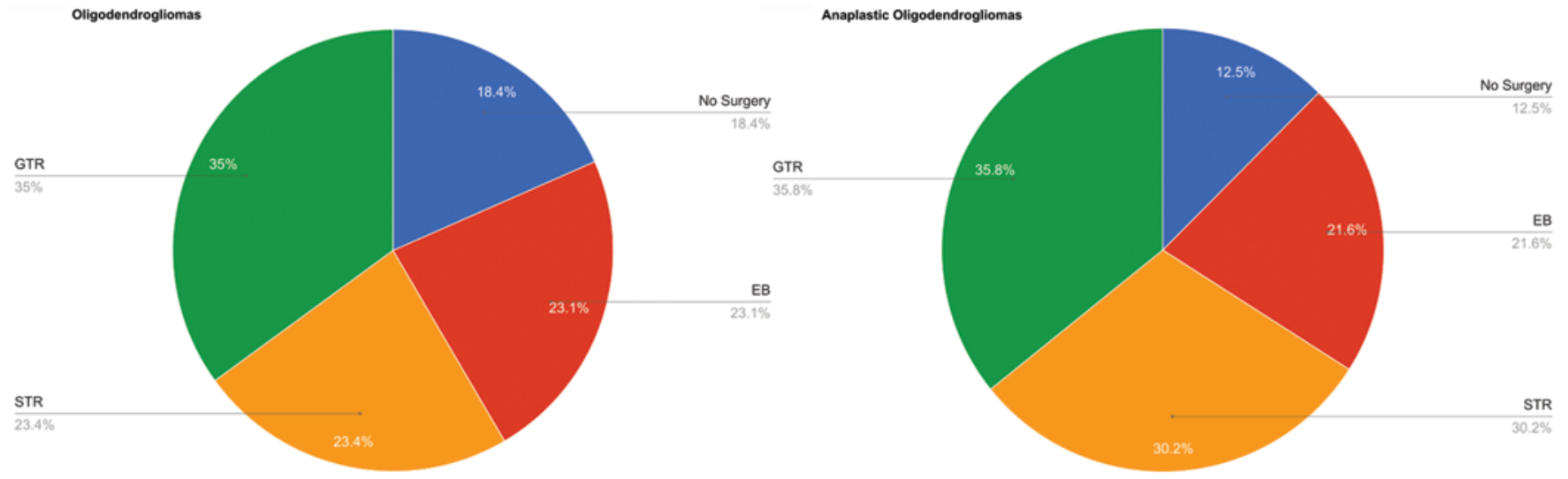

FIG. 1. Pie charts demonstrating EOR rates for O2 (left) and O3 (right) from 1999 to 2010. EB = excisional biopsy. Figure is available in color online only.

underwent biopsy only versus those with more extended resections (STR and GTR). Determination of GTR versus STR was based on radiographic reports of the postoperative MR images that were entered into the formal medical record. For patients who underwent no surgery, the tissue diagnosis was ascertained through autopsy.

Both demographic and clinical variables were included as covariates in the multivariate hazard ratio (HR) analysis. Demographic variables included sex (male or female), age $(<18,18-44,45-59,60-74$, or $>75$ years), race (White, Black, Asian/Pacific Islander, Hispanic, American Indian/ Alaskan Native, or Other/Unknown), and marital status (single; married; or separated, divorced, or widowed). Clinical variables included tumor size, tumor site, year of diagnosis, use of radiotherapy, and extent of resection (EOR: no surgery, biopsy, STR, and GTR).

\section{Literature Review Search Strategy and Eligibility Criteria}

We performed a PubMed electronic database search from 1900 to December 2015 using the following search terms: ("low-grade glioma" OR "anaplastic oligodendroglioma" OR "oligodendroglioma" OR "oligoastrocytoma") AND ("extent of resection" OR "surgical resection" OR "gross total resection" OR "tumor resection" OR "partial resection" OR "resection"[Title/Abstract]). We excluded all papers that included the word "MRI" in the title, because these papers did not focus on the effect of resection. Studies were also excluded if they met any of the following criteria: 1) not published in English; 2) focused on basic science; 3) involved nonhuman subjects; 4) focused on nonintracranial tumors; 5) focused on a tool or experimental therapy; 6 ) was an editorial, review, metaanalysis, or case report; 7) included patients $<18$ years old; 8) lacked pertinent statistical measures for assessing the association between EOR and overall survival; or 9) combined $\mathrm{O} 2 \mathrm{~s}$ and $\mathrm{O} 3 \mathrm{~s}$ into a single variable or included them with other histological tumor subtypes; if other tumor types were included in the study, information was required to be isolatable for $\mathrm{O} 2 \mathrm{~s}$ and $\mathrm{O} 3 \mathrm{~s}$. Articles meeting these criteria were identified by 2 independent reviewers (A.A.A. and M.G.B.) and results were discussed with the senior authors.

\section{Statistical Analysis}

All analyses were conducted with commercially available statistical analysis software (Stata SE, version 11.2, StataCorp LP). Statistical significance was set at $p=0.05$. Univariate analysis of patient demographics and clinical variables by tumor histology was performed using Pearson's chi-square test. Because median survival was not reached for many of the analyses, the 75th percentile patient survival time by EOR (no resection, biopsy, STR, and GTR) and tumor histology (O2 or O3) was determined..$^{15,18,24}$ Survival was assessed using unadjusted Kaplan-Meier models, and statistical significance was determined using the log-rank test. Finally, a multivariate Cox proportional hazards model was used to assess the hazard of death by EOR, adjusting for patient demographics and clinical covariates. In all comparisons, the biopsy-only category of EOR was used as the reference group.

\section{Results}

\section{Patient Demographics and Clinical Characteristics}

We identified 2378 patients with $\mathrm{O} 2$ and 1028 patients with O3. The median patient age at diagnosis was 41 years for $\mathrm{O} 2$ (interquartile range [IQR] 32-51 years) and 48 for O3 (IQR 38-58 years). The male to female ratio was approximately $1: 1$ for both $\mathrm{O} 2(1.01)$ and $\mathrm{O} 3(1.0)$. The most common sites for all oligodendroglial types were frontal and temporal lobes. Patient characteristics are described in Table 1. Of the patients with O2, $438(18 \%)$ did not undergo surgery, 550 (23\%) underwent biopsy, 557 (23\%) underwent STR, and $833(35 \%)$ underwent GTR. Of the patients with O3, 128 (12\%) did not undergo surgery, 222 (22\%) underwent biopsy, $310(30 \%)$ underwent STR, and 368 (36\%) underwent GTR (Fig. 1).

\section{Patient Survival (75th Percentile)}

Patient survival in the 75th percentile (the time in months at which $25 \%$ of the original patient population had died [75ST]) is an established end point in the study of diseases with prolonged survival. ${ }^{34-36}$ In this study, 75ST was used as an end point because the overall survival of most patients with $\mathrm{O} 2$ extended beyond the study period 

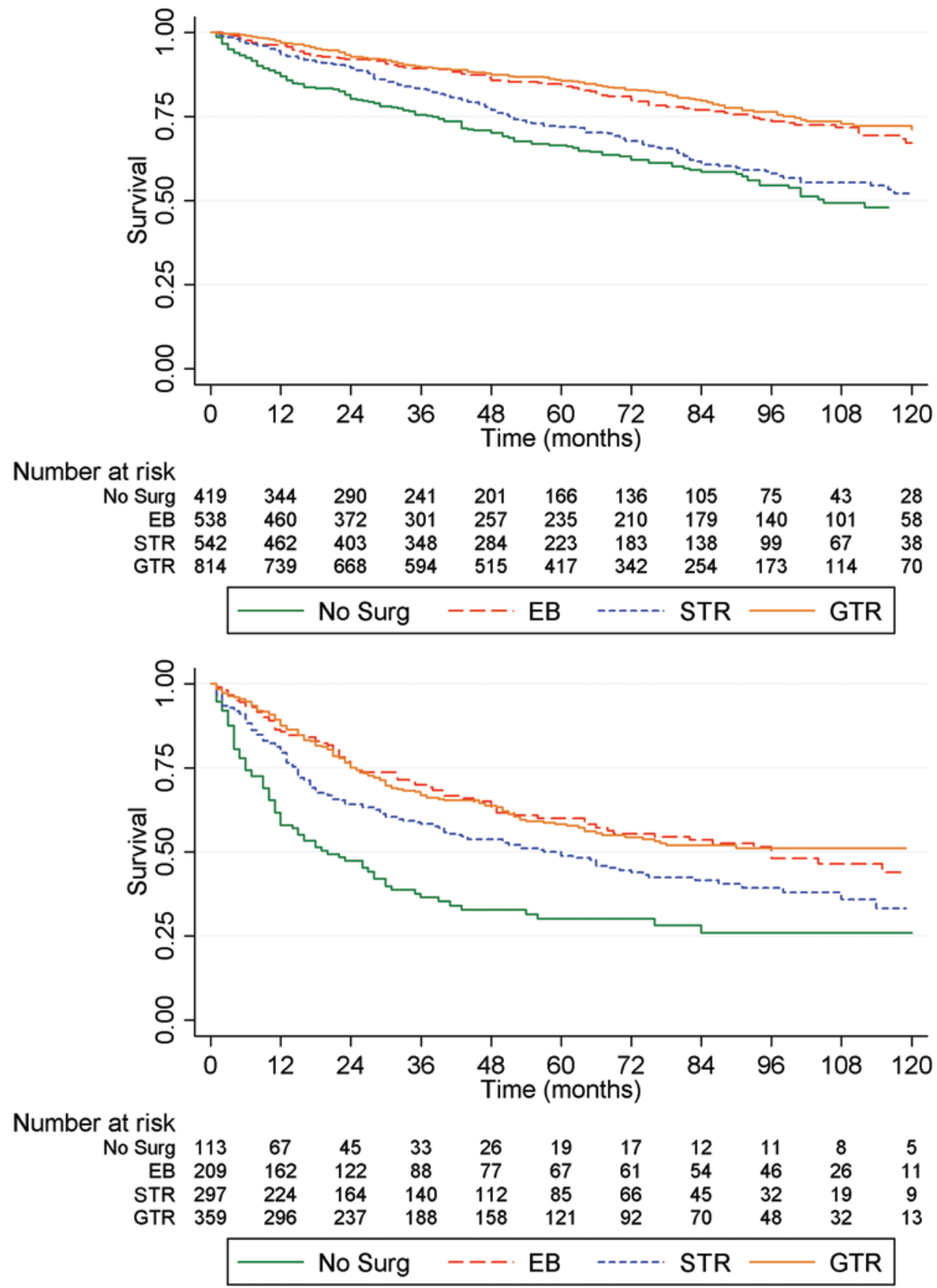

FIG. 2. Kaplan-Meier curves demonstrating survival in $\mathrm{O} 2$ (upper) and $\mathrm{O} 3$ (lower) tumors. In both graphs, the difference between the 4 curves was statistically significant according to the log-rank test $(p<0.0001)$. Figure is available in color online only.

such that there was an insufficient number of deaths to determine median survival. The $75 \mathrm{ST}$ was 72 months $(95 \%$ CI 66-79 months) for all O2s and 18 months (95\% CI 1521 months) for all O3s. The survival trends of $\mathrm{O} 2$ and $\mathrm{O} 3$ differed significantly based on log-rank testing $(p<0.001)$.

\section{Survival Analysis as a Function of Resection}

The 75ST for $\mathrm{O} 2$ was 38 months (95\% CI 28-48 months) for patients who did not undergo surgical intervention, 93 months (95\% CI 73-111 months) for patients who underwent biopsy only, 52 months (95\% CI 46-64 months) for patients who underwent STR, and 100 months (95\% CI 86-122 months) for patients who underwent GTR (Fig. 2 upper). The 75ST for O3 was 6 months (95\% CI 4-10 months) for patients who did not undergo surgical intervention, 24 months (95\% CI 21-38 months) for patients who underwent biopsy only, 15 months (95\% CI 12-17 months) for patients who underwent STR, and 24 months (95\% CI 21-30 months) for patients who underwent GTR (Fig. 2 lower). 
TABLE 2. Results of multivariate Cox proportional hazards analysis assessing risk of death with respect to differing EOR

\begin{tabular}{|c|c|c|c|c|}
\hline \multirow[b]{2}{*}{ EOR } & \multicolumn{2}{|c|}{ O2 Group } & \multicolumn{2}{|c|}{ O3 Group } \\
\hline & Adjusted HR (95\% Cl) & $p$ Value & Adjusted HR (95\% Cl) & $p$ Value \\
\hline No surgery & $1.69(1.15-2.49)$ & 0.008 & $1.85(1.18-2.91)$ & 0.008 \\
\hline Local excision/biopsy & 1 & Reference & 1 & Reference \\
\hline STR & $1.21(0.83-1.75)$ & 0.317 & $1.62(1.11-2.38)$ & 0.013 \\
\hline GTR & $1.06(0.73-1.53)$ & 0.754 & $1.18(0.80-1.72)$ & 0.404 \\
\hline
\end{tabular}

Boldface type indicates statistical significance.

\section{Cox Proportional Hazard Analysis of Survival}

To determine whether GTR is associated with increased overall survival after controlling for pertinent demographic and clinical variables, a multivariate Cox proportional hazards analysis was performed. For patients in both the $\mathrm{O} 2$ and $\mathrm{O} 3$ groups, the HR for death was comparable between the biopsy and the GTR group (Table 2). For patients with $\mathrm{O} 2$, the HR of dying from the disease was 1.06 (95\% CI $0.73-1.53)$ for patients who underwent GTR relative to those who underwent biopsy only. For patients with $\mathrm{O} 3$, the HR of dying from the disease was 1.18 (95\% CI 0.80-1.72) for patients who underwent GTR relative to those who underwent biopsy only.

\section{Literature Review}

A comprehensive review of the published literature was performed to identify studies that examined the association between extended resection and improved overall survival for patients with $\mathrm{O} 2$ and $\mathrm{O} 3$ (Fig. 3; see Meth$o d s$ ). There were 5 such papers identified for $\mathrm{O} 2$ (Table 3), $9,26,27,47,52$ Of these studies, 4 showed no association between EOR and overall survival ( $p=0.83,0.90$, nonsignificant, and nonsignificant). The 1 discordant study (Snyder et al., ${ }^{47}$ ) found an association between GTR and improved overall survival. Notably, the overall survival rate of patients who underwent GTR in this study (62\%) was worse than in other published studies and our SEER results. ${ }^{9,26,52}$ We identified 4 papers that examined the association between EOR and overall survival for O3 (Table 3). ${ }^{8,27,38,43}$ While the measures of survival differed in these studies, the 4 studies uniformly concluded there was no association between EOR and improved survival.

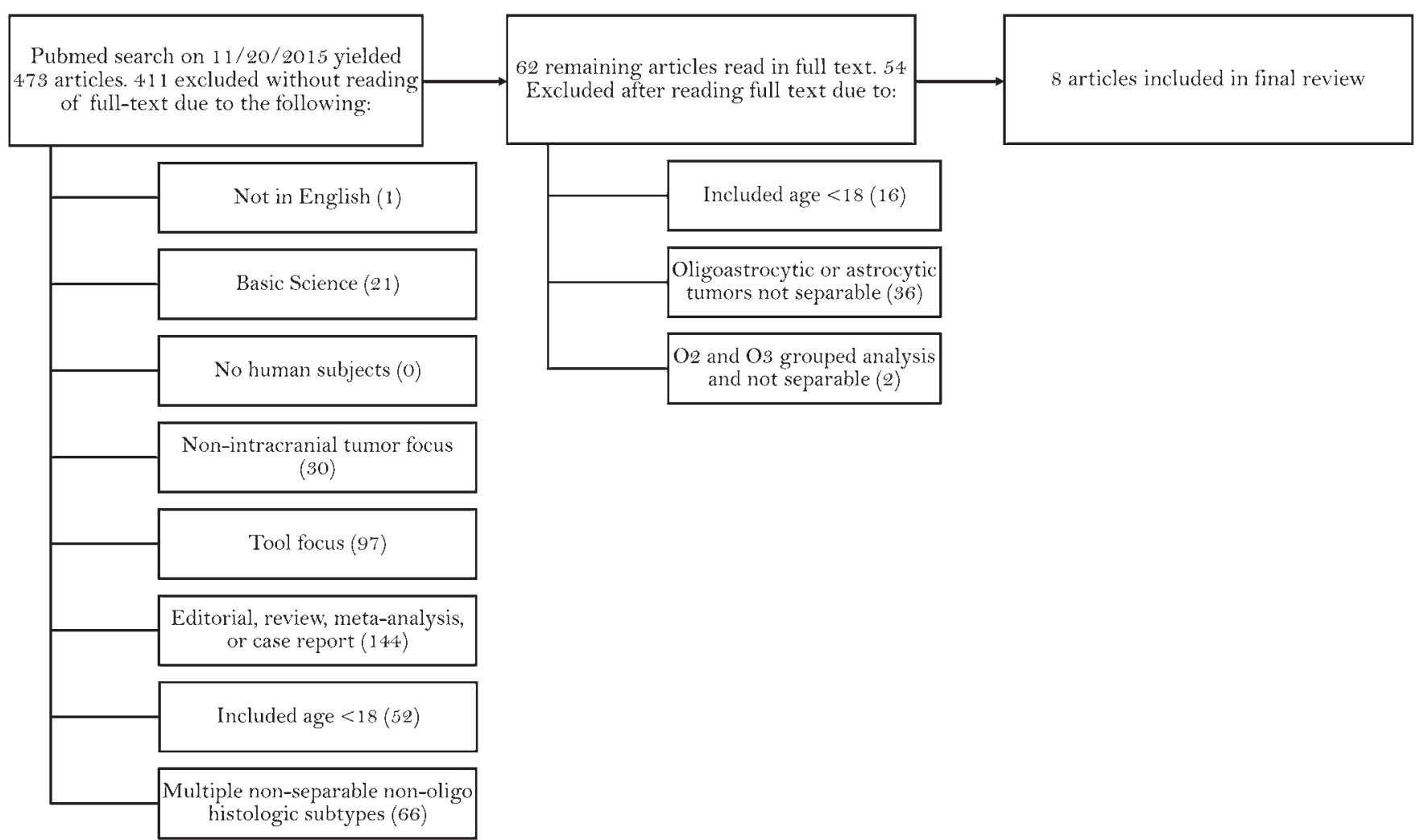

FIG. 3. Flow chart demonstrating the technique used to review the literature for articles assessing the association between EOR and survival. 
TABLE 3. Results of a review of the literature for studies assessing the association between EOR and survival

\begin{tabular}{|c|c|c|c|c|c|c|}
\hline Authors \& Year & Histological Groups & No. of Pts & Rate of GTR (\%) & Overall Survival & Comparison Group & $\mathrm{p}$ Value \\
\hline Yeh et al., 2002 & $\mathrm{O} 2$ & 52 & 13.0 & $86 \%(5-y r)$ & STR (5-yr 78\%) & 0.83 \\
\hline Lebrun et al., 2004 & $\mathrm{O} 2$ & 51 & 31.40 & NA & PR or biopsy & NS \\
\hline Lebrun et al., 2007 & $\mathrm{O} 2$ & 57 & 19.3 & NA & NA & $\mathrm{NA} \dagger$ \\
\hline El-Hateer et al., 2009 & $\mathrm{O} 2$ & 69 & 27.0 & HR 0.9 & STR & 0.9 \\
\hline Snyder et al., 2014 & 02 & 93 & $45^{*}$ & $90 \%(5-y r)$ & STR (5-yr 62\%) & 0.005 \\
\hline Durando et al., 2013 & O3 & 12 & 0.0 & $\mathrm{NA}$ & NA & NS \\
\hline Puduvalli et al., 2003 & $\mathrm{O} 3$ & 106 & 28.3 & NA & NA & NS \\
\hline Lebrun et al., 2004 & $\mathrm{O} 3$ & 49 & 24.49 & $16 \%$ & PR or biopsy & NS \\
\hline Nuño et al., 2013 & $\mathrm{O} 3$ & 570 & 36.1 & HR $1.03 \ddagger$ & Biopsy & 0.79 \\
\hline
\end{tabular}

$\mathrm{NA}=$ not available; $\mathrm{NS}=$ not significant; $\mathrm{Pts}=$ patients.

Boldface type indicates statistical significance.

* GTR defined as $>90 \%$ resection.

$\dagger$ There was no mention of EOR when significant prognostic variables were discussed, and the univariate and multivariate tables were not provided. We assume that EOR was not mentioned because it was not significant.

$\ddagger$ Hazard ratio of dying from the disease for GTR relative to patients undergoing biopsy.

\section{Discussion}

In neurooncology, surgical paradigms span the spectrum of only biopsy in tumors highly sensitive to chemotherapy and radiation, such as PCNSL, ${ }^{10-12,40}$ to maximal safe resection in HGGs. ${ }^{14,16,19,28,37,42}$ Our analysis of patients with oligodendroglioma in the SEER database suggests that the survival patterns of these tumors more closely resembles that of PCNSL than HGG. In our multivariate model, there was no difference in the hazard of death for patients with oligodendroglioma who underwent a biopsy only versus GTR. These findings are largely consistent with the sensitivity of oligodendroglioma to chemotherapy. ${ }^{2,4,13}$ Notably, the HR of death for patients with oligodendroglioma who underwent STR was found to be higher than the HR of death for those who underwent biopsy or GTR. This result suggests that the inherent patient/tumor characteristics associated with selection for STR are associated with the poor prognosis and/or morbidity associated with STR (for instance, resection terminated due to unfavorable surgical events, or postoperative hemorrhage) negatively influenced overall survival. ${ }^{23}$

The finding that GTR did not significantly affect the overall survival of patients with oligodendroglioma is largely consistent with our review of the published literature. Of the 8 articles identified, only the study by Snyder et al. suggested improvement in survival for patients with oligodendroglioma who underwent GTR ${ }^{47}$ Of note, the 5-year overall survival rate for patients who underwent GTR in the series of Snyder et al. was comparable to all other studies, including this study $(80 \%-90 \%),{ }^{9,26,52}$ In contrast, the overall survival rate of patients who underwent STR (62\%) was significantly worse than those reported in other published studies and in this report. ${ }^{9,26,52}$ Thus, the statistical difference reported by Snyder et al. was driven more by poor survival of patients who underwent STR than improved survival of patients who underwent GTR. ${ }^{47}$

Studies of rare diseases, such as oligodendroglioma, in a population-based database are particularly instructive because institutional experiences are necessarily limited in sample size. For instance, a sample size of approximate- ly 1300 patients with $\mathrm{O} 3$ would be needed to detect an improvement in survival with GTR relative to biopsy in this population. This is calculated using an $\alpha$ of $0.05, \beta$ of 0.8 , and an effect size of $10 \%$, which is based on survival estimates provided by our SEER analysis. For the same size effect, approximately 700 patients will be required for the $\mathrm{O} 2$ population; such a sample size cannot be achieved by any single institution. In contrast, the SEER database provides outcome data for approximately 2300 patients with $\mathrm{O} 2$ and 1300 patients with $\mathrm{O} 3$, allowing a sample size sufficient for detection of a $10 \%$ survival benefit related to GTR relative to biopsies in both $\mathrm{O} 2$ and $\mathrm{O} 3$ patient groups.

It is important to interpret the results reported here in the context of the shifting landscape of glioma diagnosis. Since 1999, there has been growing recognition that oligodendrogliomas exhibit favorable response to select chemotherapy regimens, ${ }^{3,28,44,50}$ and the diagnosis of oligodendroglioma qualifies the patient for treatment with these regimens. Consequently, there has been an overall increase in the number of patients diagnosed with oligodendroglioma during the period of our study. ${ }^{37}$ The available literature suggest that patients with Grade II and III astrocytomas benefit from GTR. ${ }^{7,20,22,39}$ As such, misclassification of Grade II and III astrocytomas as oligodendrogliomas would artificially inflate the survival benefit of GTR in the patients with oligodendroglioma. Despite this consideration, we did not observe any survival benefit for GTR in the patients with oligodendroglioma. In this context, we believe that our results are robust.

However, studies using population databases are not without inherent limitations, including the heterogeneity of clinical practice in participating centers. Furthermore, there is a lack of information on chemotherapeutic regimens, Karnofsky Performance Scale status, and other clinical variables in the SEER database. Additionally, the neurooncology community is largely defining oligodendroglioma based on the presence of genetic events such as isocitrate dehydrogenase mutations and $1 \mathrm{p} 19 \mathrm{q}$ loss. ${ }^{32,35,45}$ This information is not available in the current SEER database. This shortcoming is mitigated somewhat by the 
high concordance (approximately $80 \%$ for isocitrate dehydrogenase and 1p19q) between these genetic events and the histological diagnosis of oligodendroglioma. ${ }^{51}$ Another limitation of the SEER data set is that the extent of resection is subjectively assessed without volumetric quantitation. Finally, survival studies, such as the one conducted here, fail to take into consideration nonsurvival clinical benefits associated with extended resection of oligodendroglioma, such as reduction of seizure frequency, neurocognitive function, and quality of life. ${ }^{6,34}$ Nevertheless, our results provide an additional layer of consideration during surgical planning of oligodendroglioma and are of value to the neurosurgical community.

\section{Conclusions}

Our SEER-based analysis suggests that GTR is not associated with increased overall survival in patients with oligodendroglioma. This finding contrasts with prior SEER-based analyses of astrocytic tumors, including anaplastic astrocytoma and glioblastoma.

\section{References}

1. Bush NA, Chang SM, Berger MS: Current and future strategies for treatment of glioma. Neurosurg Rev 40:1-14, 2017

2. Cairncross G, Macdonald D, Ludwin S, Lee D, Cascino T, Buckner J, et al: Chemotherapy for anaplastic oligodendroglioma. J Clin Oncol 12:2013-2021, 1994

3. Cairncross G, Wang M, Shaw E, Jenkins R, Brachman D, Buckner J, et al: Phase III trial of chemoradiotherapy for anaplastic oligodendroglioma: long-term results of RTOG 9402. J Clin Oncol 31:337-343, 2013

4. Cairncross JG, Ueki K, Zlatescu MC, Lisle DK, Finkelstein DM, Hammond RR, et al: Specific genetic predictors of chemotherapeutic response and survival in patients with anaplastic oligodendrogliomas. J Natl Cancer Inst 90:1473-1479, 1998

5. Chaichana KL, McGirt MJ, Laterra J, Olivi A, QuiñonesHinojosa A: Recurrence and malignant degeneration after resection of adult hemispheric low-grade gliomas. J Neurosurg 112:10-17, 2010

6. Chang EF, Potts MB, Keles GE, Lamborn KR, Chang SM, Barbaro NM, et al: Seizure characteristics and control following resection in 332 patients with low-grade gliomas. J Neurosurg 108:227-235, 2008

7. Dong X, Noorbakhsh A, Hirshman BR, Zhou T, Tang JA, Chang DC, et al: Survival trends of grade I, II, and III astrocytoma patients and associated clinical practice patterns between 1999 and 2010: a SEER-based analysis. Neuro Oncol Pract 3:29-38, 2015

8. Durando X, Lemaire JJ, Tortochaux J, Van-Praagh I, Kwiatkowski F, Vincent C, et al: High-dose BCNU followed by autologous hematopoietic stem cell transplantation in supratentorial high-grade malignant gliomas: a retrospective analysis of 114 patients. Bone Marrow Transplant 31:559-564, 2003

9. El-Hateer H, Souhami L, Roberge D, Maestro RD, Leblanc R, Eldebawy E, et al: Low-grade oligodendroglioma: an indolent but incurable disease? Clinical article. J Neurosurg 111:265-271, 2009

10. Feiden W, Bise K, Steude U: Diagnosis of primary cerebral lymphoma with particular reference to CT-guided stereotactic biopsy. Virchows Arch A Pathol Anat Histopathol 417:21-28, 1990

11. Ferreri AJ, Reni M, Pasini F, Calderoni A, Tirelli U, Pivnik
A, et al: A multicenter study of treatment of primary CNS lymphoma. Neurology 58:1513-1520, 2002

12. Ferreri AJ, Reni M, Villa E: Therapeutic management of primary central nervous system lymphoma: lessons from prospective trials. Ann Oncol 11:927-937, 2000

13. Glass J, Hochberg FH, Gruber ML, Louis DN, Smith D, Rattner B: The treatment of oligodendrogliomas and mixed oligodendroglioma-astrocytomas with PCV chemotherapy. J Neurosurg 76:741-745, 1992

14. Gonda DD, Warnke P, Sanai N, Taich Z, Kasper EM, Chen $\mathrm{CC}$ : The value of extended glioblastoma resection: insights from randomized controlled trials. Surg Neurol Int 4:110, 2013

15. Hirsch FR, Varella-Garcia M, Bunn PA Jr, Di Maria MV, Veve R, Bremmes RM, et al: Epidermal growth factor receptor in non-small-cell lung carcinomas: correlation between gene copy number and protein expression and impact on prognosis. J Clin Oncol 21:3798-3807, 2003

16. Hirshman BR, Jones LA, Tang JA, Proudfoot JA, Carley KM, Carter BS, et al: 'Journal bias' in peer-reviewed literature: an analysis of the surgical high-grade glioma literature. J Neurol Neurosurg Psychiatry 87:1248-1250, 2016

17. Iwamoto FM, Reiner AS, Nayak L, Panageas KS, Elkin EB, Abrey LE: Prognosis and patterns of care in elderly patients with glioma. Cancer 115:5534-5540, 2009

18. Kantola S, Parikka M, Jokinen K, Hyrynkangs K, Soini Y, Alho OP, et al: Prognostic factors in tongue cancer-relative importance of demographic, clinical and histopathological factors. Br J Cancer 83:614-619, 2000

19. Keles GE, Anderson B, Berger MS: The effect of extent of resection on time to tumor progression and survival in patients with glioblastoma multiforme of the cerebral hemisphere. Surg Neurol 52:371-379, 1999

20. Keles GE, Chang EF, Lamborn KR, Tihan T, Chang CJ, Chang SM, et al: Volumetric extent of resection and residual contrast enhancement on initial surgery as predictors of outcome in adult patients with hemispheric anaplastic astrocytoma. J Neurosurg 105:34-40, 2006

21. Keles GE, Lamborn KR, Berger MS: Low-grade hemispheric gliomas in adults: a critical review of extent of resection as a factor influencing outcome. J Neurosurg 95:735-745, 2001

22. Kiliç T, Özduman K, Elmaci I, Sav A, Necmettin Pamir M: Effect of surgery on tumor progression and malignant degeneration in hemispheric diffuse low-grade astrocytomas. J Clin Neurosci 9:549-552, 2002

23. Koebbe CJ, Sherman JD, Warnick RE: Distant wounded glioma syndrome: report of two cases. Neurosurgery 48:940-944, 2001

24. Kraay MJ, Figgie MP, Inglis AE, Wolfe SW, Ranawat CS: Primary semiconstrained total elbow arthroplasty. Survival analysis of 113 consecutive cases. J Bone Joint Surg Br 76:636-640, 1994

25. Lacroix M, Abi-Said D, Fourney DR, Gokaslan ZL, Shi W, DeMonte F, et al: A multivariate analysis of 416 patients with glioblastoma multiforme: prognosis, extent of resection, and survival. J Neurosurg 95:190-198, 2001

26. Lebrun C, Fontaine D, Bourg V, Ramaioli A, Chanalet S, Vandenbos F, et al: Treatment of newly diagnosed symptomatic pure low-grade oligodendrogliomas with PCV chemotherapy. Eur J Neurol 14:391-398, 2007

27. Lebrun C, Fontaine D, Ramaioli A, Vandenbos F, Chanalet S, Lonjon M, et al: Long-term outcome of oligodendrogliomas. Neurology 62:1783-1787, 2004

28. Leibel SA, Sheline GE: Radiation therapy for neoplasms of the brain. J Neurosurg 66:1-22, 1987

29. Levin VA: Chemotherapy for brain tumors of astrocytic and oligodendroglial lineage: the past decade and where we are heading. Neuro Oncol 1:69-80, 1999

30. Lindegaard KF, Mørk SJ, Eide GE, Halvorsen TB, Hatlevoll 
R, Solgaard T, et al: Statistical analysis of clinicopathological features, radiotherapy, and survival in 170 cases of oligodendroglioma. J Neurosurg 67:224-230, 1987

31. Lote K, Egeland T, Hager B, Stenwig B, Skullerud K, BergJohnsen J, et al: Survival, prognostic factors, and therapeutic efficacy in low-grade glioma: a retrospective study in 379 patients. J Clin Oncol 15:3129-3140, 1997

32. Louis DN, Perry A, Burger P, Ellison DW, Reifenberger G, von Deimling A, et al: International Society Of Neuropathology-Haarlem consensus guidelines for nervous system tumor classification and grading. Brain Pathol 24:429-435, 2014

33. Louis DN, Perry A, Reifenberger G, von Deimling A, Figarella-Branger D, Cavenee WK, et al: The 2016 World Health Organization Classification of Tumors of the Central Nervous System: a summary. Acta Neuropathol 131:803-820, 2016

34. Luyken C, Blümcke I, Fimmers R, Urbach H, Elger CE, Wiestler OD, et al: The spectrum of long-term epilepsyassociated tumors: long-term seizure and tumor outcome and neurosurgical aspects. Epilepsia 44:822-830, 2003

35. Masui K, Mischel PS, Reifenberger G: Molecular classification of gliomas. Handb Clin Neurol 134:97-120, 2016

36. Ng K, Kim R, Kesari S, Carter B, Chen CC: Genomic profiling of glioblastoma: convergence of fundamental biologic tenets and novel insights. J Neurooncol 107:1-12, 2012

37. Noorbakhsh A, Tang JA, Marcus LP, McCutcheon B, Gonda DD, Schallhorn CS, et al: Gross-total resection outcomes in an elderly population with glioblastoma: a SEER-based analysis. J Neurosurg 120:31-39, 2014

38. Nuño M, Birch K, Mukherjee D, Sarmiento JM, Black KL, Patil CG: Survival and prognostic factors of anaplastic gliomas. Neurosurgery 73:458-465, 2013

39. Okamoto Y, Di Patre PL, Burkhard C, Horstmann S, Jourde B, Fahey M, et al: Population-based study on incidence, survival rates, and genetic alterations of low-grade diffuse astrocytomas and oligodendrogliomas. Acta Neuropathol 108:49-56, 2004

40. O’Neill BP, Kelly PJ, Earle JD, Scheithauer B, Banks PM: Computer-assisted stereotaxic biopsy for the diagnosis of primary central nervous system lymphoma. Neurology 37:1160-1164, 1987

41. Ostrom QT, Gittleman H, Fulop J, Liu M, Blanda R, Kromer C, et al: CBTRUS Statistical Report: Primary Brain and Central Nervous System Tumors Diagnosed in the United States in 2008-2012. Neuro Oncol 17 (Suppl 4):iv1-iv62, 2015

42. Padwal JA, Dong X, Hirshman BR, Hoi-Sang U, Carter BS, Chen CC: Superior efficacy of gross total resection in anaplastic astrocytoma patients relative to glioblastoma patients. World Neurosurg 90:186-193, 2016

43. Puduvalli VK, Hashmi M, McAllister LD, Levin VA, Hess KR, Prados M, et al: Anaplastic oligodendrogliomas: prognostic factors for tumor recurrence and survival. Oncology 65:259-266, 2003

44. Ramirez C, Bowman C, Maurage CA, Dubois F, Blond S, Porchet N, et al: Loss of 1p, 19q, and 10q heterozygosity prospectively predicts prognosis of oligodendroglial tumorstowards individualized tumor treatment? Neuro Oncol 12:490-499, 2010

45. Reuss DE, Sahm F, Schrimpf D, Wiestler B, Capper D, Koelsche C, et al: ATRX and IDH1-R132H immunohistochemistry with subsequent copy number analysis and IDH sequencing as a basis for an "integrated" diagnostic approach for adult astrocytoma, oligodendroglioma and glioblastoma. Acta Neuropathol 129:133-146, 2015

46. Shaw E, Arusell R, Scheithauer B, O'Fallon J, O'Neill B, Dinapoli R, et al: Prospective randomized trial of low- versus high-dose radiation therapy in adults with supratentorial low-grade glioma: initial report of a North Central Cancer Treatment Group/Radiation Therapy Oncology Group/ Eastern Cooperative Oncology Group study. J Clin Oncol 20:2267-2276, 2002

47. Snyder LA, Wolf AB, Oppenlander ME, Bina R, Wilson JR, Ashby L, et al: The impact of extent of resection on malignant transformation of pure oligodendrogliomas. J Neurosurg 120:309-314, 2014

48. Sun ZM, Genka S, Shitara N, Akanuma A, Takakura K: Factors possibly influencing the prognosis of oligodendroglioma. Neurosurgery 22:886-891, 1988

49. Suneja G, Alonso-Basanta M, Lustig R, Lee JY, Bekelman JE: Postoperative radiation therapy for low-grade glioma: patterns of care between 1998 and 2006. Cancer 118:37353742,2012

50. van den Bent MJ: Practice changing mature results of RTOG study 9802: another positive PCV trial makes adjuvant chemotherapy part of standard of care in low-grade glioma. Neuro Oncol 16:1570-1574, 2014

51. Yan H, Parsons DW, Jin G, McLendon R, Rasheed BA, Yuan W, et al: IDH1 and IDH2 mutations in gliomas. N Engl J Med 360:765-773, 2009

52. Yeh SA, Lee TC, Chen HJ, Lui CC, Sun LM, Wang CJ, et al: Treatment outcomes and prognostic factors of patients with supratentorial low-grade oligodendroglioma. Int J Radiat Oncol Biol Phys 54:1405-1409, 2002

\section{Disclosures}

The authors report no conflict of interest concerning the materials or methods used in this study or the findings specified in this paper.

\section{Author Contributions}

Conception and design: Chen, Alattar, Brandel, Hirshman, Dong, Carter. Acquisition of data: Chen, Alattar, Brandel, Hirshman, Dong. Analysis and interpretation of data: Chen, Alattar, Brandel, Hirshman, Carter. Drafting the article: Chen, Alattar, Brandel, Hirshman. Critically revising the article: Chen, Alattar, Brandel, Hirshman, Carroll, Ali, Carter. Reviewed submitted version of manuscript: Chen, Alattar, Brandel, Hirshman, Dong, Carroll, Carter. Approved the final version of the manuscript on behalf of all authors: Chen. Statistical analysis: Alattar, Hirshman. Administrative/technical/material support: Ali. Study supervision: Chen, Carter.

\section{Supplemental Information}

\section{Previous Presentations}

Portions of this work were presented in poster form at the CNS Annual Meeting, San Diego, California, September 24-28, 2016.

\section{Correspondence}

Clark C. Chen, Division of Neurosurgery, University of California, San Diego, 3855 Health Science Dr., \#0987, La Jolla, CA 92093-0987. email: clarkchen@ucsd.edu. 